\section{Biochemical and nutritional characteristics of buffalo meat and potential implications on human health for a personalized nutrition}

\author{
Andrea Tamburrano, ${ }^{1}$ \\ Barbara Tavazzi, ${ }^{1,2}$ \\ Cinzia Anna Maria Callà, ${ }^{1,2}$ \\ Angela Maria Amorini, ${ }^{3}$ \\ Giacomo Lazzarino, ${ }^{1}$ \\ Sara Vincenti, ${ }^{2}$ Tiziana Zottola, ${ }^{4}$ \\ Maria Concetta Campagna, ${ }^{4}$ \\ Umberto Moscato, ${ }^{1,2}$ \\ Patrizia Laurenti ${ }^{1,2}$ \\ ${ }^{1}$ Università Cattolica del Sacro \\ Cuore, Rome; ${ }^{2}$ University Hospital \\ A. Gemelli - IRCCS, Rome; \\ ${ }^{3}$ University of Catania; \\ ${ }^{4}$ Experimental Zooprophylactic \\ Institute of Lazio e Toscana \\ "M. Aleandri", Latina, Italy
}

\section{Abstract}

The human consumption of food animal products is the main topic of an important debate among professionals in this sector: dietologists, dietitians and nutritional biologists. The red meat provides all the essential amino acids, bioavailable iron, zinc, calcium, lipids and B-group vitamins. A valid alternative to beef could be the buffalo meat. Italy is the largest European producer of buffalo meat and derivatives. The high nutritional characteristics of buffalo meat make it suitable to be included in the Mediterranean diet to customize it in relation to the needs and conditions of the population. Polyunsaturated/saturated fatty acids ratio can be influenced by diet, breed and type of breeding, but muscle tissue fat percentage is the main factor in determining a favorable fatty acid composition. This review focuses on the biochemical and nutritional characteristics of the buffalo meat (content of fats, cholesterol, amino acids, vitamins and minerals), explaining their variability depending on the different breeds, and the favorable implications on the human health. These results suggest that buffalo meat can be a healthier alternative to beef, not only for healthy people in particular physiological conditions (i.e. pregnancy), but also for persons at risk for cardiovascular and cerebrovascular diseases, thus achieving the goal of a personalized nutrition.

\section{Introduction}

Nowadays, the consumption of animal origin products in human nutrition is the main topic of an important debate among professionals: dietologists, dieticians, nutritional biologists and hygienists. Many scientific works, in which observational studies and physio-pathological findings have been carried out, show a correlation between the intake of meat and meat-based products and the onset of degenerative, cardiovascular, cerebrovascular and tumor diseases (Keys, 1980; Barnard et al., 1995; Brunner et al., 2008; Trichopoulou et al., 2009). However, these data must be related to the frequency of intake of the food, the nutritional value and the lifestyle of the population. In particular, red meat provides all the essential amino acids, highly bioavailable heme iron, zinc, calcium, lipids and B-group vitamins (specifically vitamin B12 involved, for example, in brain development and prevention of pernicious anemia). During the evolution of the species, men used hunting, fishing and wild fruit gathering as food source. Currently many populations follow almost the same diet. Cordain et al. (2002) reported that 229 hunter-gatherer populations, whose diet was made up of $26-35 \%$ of vegetables and $66-$ $75 \%$ of animal origin products, were not affected by cardiovascular diseases.

In the world, the per capita consumption of beef (according to the statistical index of apparent consumption that includes inedible parts, drops in processing and various waste) is gradually being reduced, even in the large countries producing red meat such as South America, USA, Australia, Canada and New Zealand (Assocarni, 2018a)

In Europe, in the last 5 years, the trend of apparent per capita consumption of beef has undergone an inconstant trend, with a slight decline in the years 2013-2014, stabilizing at a consumption of $15.6 \mathrm{~kg}$ per capita per year in 2016 -2017 (Assocarni, 2018b).

In Italy, in the last 10 years, a clear reduction in apparent consumption of beef has been reported: it decreased from $24.9 \mathrm{~kg}$ per capita per year in 2007 to $17.1 \mathrm{~kg}$ per capita per year in 2017 (Assocarni, 2018c).

A valid alternative to beef could be buffalo meat. Italy is the first European country for buffaloes breeding. The current size of the Italian buffalo heritage is 403,093 animals, distributed in a total of 2208 farms (Anagrafe Nazionale Zootecnica Statistiche, 2018). The buffalo breed in Italy belongs to the Italian Mediterranean breed,
Correspondence: Andrea Tamburrano, Università Cattolica del Sacro Cuore di Roma, Istituto di Sanità Pubblica - Sezione di igiene, Largo Francesco Vito 1, 00168 Roma, Italia. Tel.: +39.329.0659841

E-mail: andrea.tamburrano01@icatt.it

Key words: buffalo meat, biochemical properties, nutritional properties, personalized nutrition, human health

Contributions: Conceptualization, PL, and $\mathrm{UM}$; methodology, BT, TZ and CAMC; formal analysis, AT and $\mathrm{MCC}$; investigation, MCC, GL and SV; resources, TZ, PL and UM; data curation, AT, MCC, AMA, GL and SV; original draft preparation, AT, MCC, AMA and GL; review and editing, SV and MCC; supervision, PL; project administration, BT, CAMC, TZ and UM. All authors read and approved the final manuscript.

Conflict of interests: the authors declare no potential conflict of interests.

Funding: none.

Received for publication: 30 May 2019. Revision received: 31 July 2019.

Accepted for publication: 28 August 2019.

This work is licensed under a Creative Commons Attribution-NonCommercial 4.0 International License (CC BY-NC 4.0).

(C) Copyright: the Author(s), 2019

Licensee PAGEPress, Italy

Italian Journal of Food Safety 2019; 8:8317

doi:10.4081/ijfs.2019.8317

typically used to produce milk, which is then transformed into mozzarella and to a lesser extent into provola, scamorza, caciotta and caciocavallo (typical Italian cheeses). The use of buffalo in meat production, on the other hand, only affects a small production niche. Only a few breeders, in fact, dedicate themselves to male calves breeding, because of a lower growth index than the bovine species, even though the feed conversion ratio is almost identical.

Recent scientific evidence presents Foodomics as a new vision, based on Metabonomics and Proteomics, to deepen inside the effects of digestion and to compare the different digestibility and bioavailability of protein-rich foods, developing a new concept of the nutritional value of food (Bordoni et al., 2014). Food of plant and animal origin, including meat, contains bioactive peptides, released during gastrointestinal digestion or during food processing, that exhibit many positive effects on human body (i.e. antioxidative, antimicrobial, antihypertensive, antithrombotic, 
cytomodulatory, immunomodulatory, anticancer, hypocholesterolemic and antiobesity) (Baltic et al., 2014; Ferranti et al., 2014; Chakrabarti et al., 2018).

Bordoni et al. (2014) and Marcolini et al. (2015) suggest the first combined application of Bradford and SDS-PAGE assays, combined to NMR spectroscopy and relaxometry for the evaluation of protein bioavailability in bresaola, a typical meat-based food of northern Italy, after in vitro digestion. In this way it was possible to evaluate changes in nutritional values and in protein bioavailability occurring in meat-based food during digestion process. No studies on bio-accessibility and bio-availability of buffalo meat nutrients are available so far.

On the other hand, the nutritional and organoleptic characteristics of buffalo meat give it a high dietary value and make it suitable to be included in the Mediterranean diet, in case of personalized nutritional health needs.

Ordovas et al. (2018) defined Personalized Nutrition as "an approach that uses information on individual characteristics to develop targeted nutritional advice, products, or services". Personalized nutrition refers to tailored nutritional recommendations aimed at the promotion, maintenance of health and diseases prevention. These recommendations consider differential responses to certain individualized food-derived nutrients that arise due to the interaction between nutrients and biological processes (internal factors such as genetics, microbiome, metabolome interactions, and external factors such as dietary habits and physical activity) (Verma et al., 2018).

\section{Biochemical and nutritional characteristics of buffalo meat}

Biochemical and nutritional characteristics of buffalo meat have been investigated by various researchers. They focused on the evaluation of its content in cholesterol, fatty acids, amino acids, vitamins, and minerals. Meat characteristics are also significantly influenced by breeding methods that include animal feeding.

\section{Cholesterol and fatty acids composition}

Given the implications on human health and product quality, in the last decades increasingly sophisticated techniques have been used to study the composition of fatty acids and the levels of cholesterol present in the meat of animals meant for food consumption.

The buffalo carcass has a different distribution of fat than cattle carcass. In buffalo meat the fat cover is prevalent, and it is con- centrated in the subcutaneous area with few infiltrations in the muscular tissue; vice versa, in the beef, the fat infiltrates the muscular masses (typical marbling of the meat). This means that, at the time of consumption, the fat on the outer surface of the buffalo meat is easily detachable from the lean part.

The ratio of polyunsaturated/saturated fatty acids in the meat of ruminants is unfavorably low, as the unsaturated fatty acids that come from the animal's diet are hydrogenated by rumen microorganisms. This ratio, in relation to the nutritional value of food, is considered an important factor for the human health. The recommended range is 0.45-0.65 (Department of Health and Social Security, 1994); a lower ratio in an individual's diet can increase the incidence of cardiovascular and cerebrovascular diseases.

Larick et al. (1992) examined buffalo and bovine meat samples, finding differences in the composition of unsaturated and polyunsaturated fatty acids. Monounsaturated fatty acids, in their cis configuration, lower the cholesterol levels and do not reduce the high-density lipoprotein (HDL), a protecting factor against coronary heart disease.

For this reason, the main objective of the new strategies for animal feeding, both for ruminants and non-ruminants, is to increase the concentration of polyunsaturated fatty acids and the levels of conjugated linoleic acid (CLA) in fodder (in particular those of the n-3 series) and to reduce the concentration of saturated fatty acids (mainly present in animal feeds) (Scollan et al., 2006).

The type and proportion of the different fatty acids depend on the type of the evaluated muscle. Calabrò et al., (2014) observed significant differences comparing three types of muscle $(\mathrm{P}<0.01)$. The Semitendinosus muscle showed better quality indices and a better fatty acid profile with lower SFA, higher PUFA, MUFA, $\omega-6$, $\omega-3$, and CLA.

Infascelli et al. (2005), in their research, evaluated the cholesterol content and the acidic composition of intramuscular fat in the meat of buffalo and beef steers belonging to the Marchigiana breed (from Marche region of Italy). For this research the following animals were recruited: 8 buffalo steers on the fed a TMR with $14.1 \% \mathrm{CP}$ and $0.84 \mathrm{UFV} / \mathrm{Kg} \mathrm{DM}$ and 18 beef calves, belonging to the Marchigiana breed, fed diet with $15 \% \mathrm{CP}$ and $0.91 \mathrm{UFV} / \mathrm{Kg} \mathrm{DM}$. The animals were slaughtered at an average live weight (PV) of $400 \mathrm{~kg}$ and $620 \mathrm{~kg}$ respectively and the analytical investigations were carried out on the Longissimus dorsi muscle. The protein content was overlapping; the buffaloes also showed lipid concentrations of $1.36 \%$ vs $2.40 \%$ of the
Marchigiana cattle, cholesterol levels equal to 48.8 vs $53.7 \mathrm{mg} / 100 \mathrm{~g}$, (SFA) levels of $38.4 \%$ vs $46.6 \%$, MUFA levels of $37.3 \%$ vs $31.2 \%$, PUFA levels of $24.3 \%$ vs $22.3 \%$, n6 fatty acids levels of $23.7 \%$ vs $21.5 \%$. Therefore, the atherogenicity index (IA) and the thrombogenicity index (IT) were significantly lower in the buffalo species (IA of 0.41 vs 0.57 and IT of 1.16 vs 1.36).

Lambertz et al. (2014), on the other hand, investigated the characteristics of the carcasses and the quality of the buffalo meat in the Swamp subspecies, widely distributed in Thailand, bred as a working animal, to supply manure used as fuel and fertilizer and for meat production.

The presence of n-3 and n-6 fatty acids, as well as conjugated linoleic acid, helps to determine the nutritional quality of buffalo meat. The $\mathrm{n}-3$ fatty acids, in particular, have the ability to reduce the serum concentration of triglycerides in humans (Lambertz et al., 2014).

The polyunsaturated/saturated fatty acids ratio is influenced by diet, breed and type of farming. However, the percentage of fat mass in muscle tissue remains the main factor in determining the fatty acid composition and consequently the polyunsaturated/saturated fatty acids ratio (Cifuni et al., 2014).

\section{Amino acid composition}

(Landi et al., 2016) analyzed meat samples (Longissimus dorsi) of male buffaloes collected from Campania region in Italy (Bubalus bubalis) and confirmed that water buffalo meat has great advantages for human consumption because of the better protein composition $(21.13 \mathrm{~g} / 100 \mathrm{~g})$ than beef meat (19.23 g/100 g) (USDA, 2015). The total free amino acid content for $100 \mathrm{~g}$ meat ranged 155.79 to $181.78 \mathrm{mg}$.

The amounts of essential amino acids (histidine, isoleucine, leucine, lysine, methionine, phenylalanine, threonine, valine, and tryptophan) ranged 8.52 to $10.36 \mathrm{mg} / 100 \mathrm{~g}$.

Glutamic acid was the most abundant among the free amino acids (34.66-45.76\%) as well as alanine. Among the free amino acids, glycine, arginine, and asparagine were highly present.

Moreover, non-essential amino acids were identified (3.36-5.01 mg/100 g). Ethanolamine, $\beta$-alanine, and ornithine were the most abundant compounds. Finally, taurine (2-aminoethanesulfonic acid) and urea were highly present, with $17.9 \%$ and $14.8 \%$ of the total, respectively.

The total amounts of carnosine $(\beta$ alanyl-L-histidine) ranged 124.73 to 139.2 $\mathrm{mg} / 100 \mathrm{~g}$, whereas the content of anserine ( $\beta$-alanyl-N-methylhistidine) ranged 13.79 to $25.59 \mathrm{mg} / 100 \mathrm{~g}$. Furthermore, the content 
of carnosine and anserine represents $50 \%$ of the total free amino acids.

Ilavarasan et al. (2016) analyzed the amino acid content of 12 male Toda buffalos. The glutamic acid was found to be higher (1.80-2.22 g/100 g) followed by lysine $(0.84-1.07 \mathrm{~g} / 100 \mathrm{~g})$ and aspartic acid (0.89-1.05 mg/100 g). Similar results were recorded by Syed Ziauddinet al. (1994). The results of this study revealed that Toda buffalo meat is a rich source of all essential and non-essential amino acids.

Finally, these analyses show that water buffalo meat is a source of carnosine, a natural anti-aging constituent of the human body (Gariballa, 2000).

\section{Vitamins}

In 1997 analyzed 12 buffaloes for content of selected vitamins and selenium. The buffaloes came from the United States and Canada and consumed concentrate diets plus hay free choice for at least 180 days.

The mean nutrient concentrations (per 100 grams of wet weight) were as follows: $0.045 \mathrm{mg}$ thiamine (vitamin B1), $0.253 \mathrm{mg}$ pyridoxine (vitamin B6), $2.131 \mathrm{mg}$ cobalamin (vitamin B12), no detectable vitamin C, $0.848 \mathrm{mg}$ vitamin A, $0.047 \mathrm{mg}$ a-tocopherol (vitamin E), $0.013 \mathrm{mg} \beta$-tocopherol (vitamin E), and $25.464 \mathrm{mg}$ selenium. All vitamin content of the buffalo cuts was lower than those of beef, pork, chicken, and turkey (except for vitamin A, and sometimes vitamin B12).

The consumption of $100 \mathrm{~g}$ of buffalo composite cuts (raw) would provide approximately (of the Dietary Reference Intake): $3 \%$ of vitamin $\mathrm{B} 1,12.7 \%$ of vitamin $\mathrm{B} 6$, $35.5 \%$ of vitamin B12, negligible for vitamin $\mathrm{A}$ and $\mathrm{E}$, no vitamin C (Intakes, 2011).

The nutrient content data were for raw or uncooked buffalo cuts. Cooked buffalo cuts most likely would be rich sources of selenium and vitamin B12 and good sources of vitamin B6. The buffaloes were given relatively low levels of vitamins as part of their feeding regimen. Producers should consider adding a supplement containing adequate quantities of the vitamins to the diets of buffalo.

Galbraith et al. (2006) analyzed buffalo meat samples from the USA. They found a vitamin A content in all buffalo cuts 1.74 to $2.46 \mu \mathrm{g} / 100 \mathrm{~g}$, which was $2-3$ times higher than the average value of $0.848 \mu \mathrm{g} / 100 \mathrm{~g}$ reported by Driskell et al. (1997). The vitamin A content was similar in all cuts.

In 2000, Driskell et al. focused on riboflavin (vitamin B2) and niacin (vitamin B3) concentrations of 24 buffaloes that were raised in various geographic areas of the United States and Canada. The analyzed cuts contained $5.5 \%$ of the daily requirement for riboflavin $(1.7 \mathrm{mg} / 100 \mathrm{~g})$ and $9.6 \%$ for niacin $(20 \mathrm{mg} / 100 \mathrm{~g})$ (Intakes, 2011). Buffalo meat was lower than the other meats in riboflavin and niacin contents.

The nutrient content of meat does vary considerably depending on many factors, including genetics, age, feed, and time of year slaughtered. A relevant variation also in riboflavin and niacin from individual buffaloes was found. Furthermore, appreciable quantities of vitamins are known to be lost during the cooking of foods (Driskell et al., 2000).

\section{Minerals}

In 2017, Joele et al. analyzed minerals in meat from Longissimus thoracis muscle of 30 crossbred male Murrah X Mediterranean buffaloes (Bubalus bubalis). They found and analyzed a series of micronutrients (iron, copper, zinc and selenium) and contaminants (aluminum and antimony).

All samples had contents in micronutrients above the recommendation by the United States Department of Agriculture (USDA - nutrient database, 2010) of $1.61 \mathrm{~g}$ $\mathrm{kg}^{-1.48}$, which confirms that $100 \mathrm{~g}$ of buffalo meat supplies the daily requirements of these micronutrients.

Giuffrida-Mendoza et al. (2007) analyzed mineral composition of Longissimus dorsi thoracis of 64 water buffalo and 68 Zebu-influenced cattle. Water buffalo had higher concentrations in $\mathrm{K}, \mathrm{Mn}, \mathrm{Fe}, \mathrm{Zn}, \mathrm{Cu}$ and $\mathrm{P}$ (Fe ranged 1.74 to $2.56 \mathrm{mg} / 100 \mathrm{~g}$ of fresh tissue). Meat contributes to over $25 \%$ of an adult's daily requirement of K, P, Fe, and $\mathrm{Zn}$ (Intakes, 2011).

Zhang et al. (2016) analyzed the muscle tissue gene expression, including iron ion metabolism, in water buffalo and in domestic cattle. They found an increased expression of genes involved in iron homeostasis and transport, that indicates it's very important for maintaining muscle structure and function. The higher mRNA expression of genes involved in iron ion homeostasis was found in buffalo muscle than cattle such as TF (transferrin), and FTL (ferritin, light polypeptide) which is noteworthy.

Considering buffaloes as draft animals, they probably store more iron to ensure that they have sufficient myoglobin in muscle tissue for their heavier workloads, since it is needed for providing oxygen to the working muscles and its storage (Mancini \& Hunt, 2005).

The darker color of the buffalo meat is usually attributed to a higher myoglobin content (Tateo et al., 2007). This charac- teristic is associated with the high levels of iron $(\mathrm{Fe})$ homeostasis genes expressed in buffalo muscle tissues (Zhang et al., 2016).

\section{Breeding methods}

Breeding methods of buffalo are various in different countries, as well as the breeds are varied. The main breeds in the world come from the water buffalo (or Asian buffalo - Bubalus bubalis), with two subspecies, river buffalo and swamp buffalo, that differ for behavioral, morphological and genetic features (50 chromosomes in river $v s 48$ chromosomes in swamp type) and territorial distribution. The river buffalo is bred mainly in Europe, Egypt, Asia, China, Australia, South America and in some African countries. The swamp buffalo is bred mainly in China and India. In Italy there is only one breed: the Mediterranean, which derives from the river buffalo of Asian origin (Borghese, 2005, 2013).

Over the last decade, numerous researchers have studied the chemical-physical and nutritional properties of buffalo meat of the Italian Mediterranean breed, detecting different characteristics in relation to the type of feed.

The fatty acid composition of the meat is mainly influenced by the farming system (grazing or stable) and by the type, quantity and quality of the plants and feed that make up the diet (simple or composed, administered as a single meal or split during the day) (Lambertz et al., 2014). For this reason, the main objective of the new strategies for animal feeding, both for ruminants and non-ruminants, is to increase the concentration of polyunsaturated fatty acids and the levels of conjugated linoleic acid in fodder (in particular those of the n-3 series) and to reduce the concentration of saturated fatty acids (mainly present in animal feeds) (Scollan et al., 2006).

Calabrò et al. (2014) evaluated the influence of a fava bean diet (Vicia faba var. minor) on the nutritional characteristics of buffalo meat. The different type of diet has influenced the qualitative characteristics of the meat analyzed. The meat taken from buffalo fed with fava beans (FB) showed lower values of fat, protein and cholesterol compared to the meat of buffalo fed with soybeans $(\mathrm{P}<0.05)$. Furthermore, the considered parameters were visibly different depending on the type of muscle observed $(\mathrm{P}<0.001)$; in particular, the Semitendinosus (ST) muscle has the lowest fat content $(\mathrm{P}<0.01)$, while the Iliopsoas muscle contains the highest amount of protein $(\mathrm{P}<0.01)$. 


\section{Effects on health}

In 2010 Giordano et al. published a longitudinal observational study on the usual intake of buffalo meat in the diet of 300 adults, divided into 3 groups of 100 individuals (non-consumers, recent consumers and regular consumers of buffalo meat), resident in the Campania region, non-smokers, with no dyslipidemia or type-2 diabetes mellitus.

After 12 months, regular consumers showed a better lipidic profile in their blood, with lower levels of total cholesterol, high levels of HDL and low levels of triglycerides, compared to recent consumers and non-consumers. Furthermore, the same group of adults showed a better oxidative-reductive homeostasis and an improvement of the parameters associated with cardiovascular events, such as reduction of the sphygmic wave speed, of the carotid intima-media thickness and atheromatous plaques.

During the study, regular consumers of buffalo meat did not show an increase in cardiovascular diseases, unlike those who never consumed buffalo meat, in which there was a statistically significant increase in cardiovascular diseases. As a final point, recent consumers presented intermediate values, since they had begun to consume buffalo meat only during the research.

Evaluating the impact on the cardiovascular risk profile related to the intake of buffalo meat, Giordano et al. (2010) concluded that the transition from a beef-based diet to a buffalo meat-based diet seems to be associated, after a few weeks, to an improvement of the different markers of cardiovascular risk, thus detecting a more favorable serum lipidic profile, a lower atherosclerotic involvement at carotid level and a lower susceptibility to oxidative stress.

In $2013 \mathrm{McDaniel}$ et al. conducted a randomized trial to examine the consequence of a single $12 \mathrm{oz}$ serving and 7 weeks of chronic consumption of beef and buffalo on a total of 14 healthy male subjects. Blood lipids, inflammatory markers, oxidative stress and endothelial function were monitored.

After a single meal, buffalo, in contrast to beef, resulted in an attenuated increase in triglycerides, but no elevation in oxidative stress and vascular function were observed. Moreover, after 7 weeks of buffalo consumption, reduced inflammation, lower oxidative stress and a better vascular function were observed, compared to beef consumption. Authors concluded that consumption of buffalo meat, both acutely and chronically, was associated with a lower atherogenic risk than consumption of equal portions of beef (buffalo meat did not generate an increased inflammation and oxidative stress or a decreased vascular function).

The two studies reported, comparing the cardiovascular health risks associated with the acute and chronic consumption of buffalo, showed this meat a healthier alternative, in a society where red meat is widely consumed.

Personalized nutrition is equally applicable to patients and to healthy people who may or may not have enhanced genetic susceptibilities to specific diseases and can be applied in two broad areas: firstly, for the dietary management of people with specific diseases or who need special nutritional support (i.e. pregnancy, old age) and, secondly, for the development of more effective interventions aimed at improving the public health.

In this perspective buffalo meat consumption, which has a favorable content in Zn, Cholesterol and B-complex vitamins, can meet women's nutritional needs (Ordovas et al., 2018). High contents in Selenium and Iron, can extend the concept of personalized nutrition, that requires further investigations.

Table 1. Comparison of the chemical characteristics between buffalo and beef Longissimus dorsi muscle (adapted from Infascelli et al., 2009 with permission).

\begin{tabular}{lcc} 
Chemical characteristics & Buffalo & Beef \\
Water (\%) & 74.2 & 72.0 \\
Protein (\%) & 21.2 & 21.3 \\
\hline Fat (\%) & 1.6 & 5.3 \\
Cholesterol (mg/100g) & 41.3 & $60-90$ \\
\hline Ash (\%) & 1.0 & 0.8 \\
pH & 5.4 & 5.6 \\
\hline
\end{tabular}

Table 2. Comparison of the fatty acid profiles between buffalo and beef Longissimus dorsi muscle (adapted from Infascelli et al., 2009 with permission).

\begin{tabular}{lcccc} 
Fatty acids composition & \multicolumn{1}{c}{ Buffalo } & \multicolumn{2}{c}{ Beef } \\
C14 & 15.3 & 1.9 & 9.9 & 1.4 \\
C16 & 159.3 & 23.0 & 143.9 & 20.0 \\
\hline C18 & 189.3 & 21.1 & 117.7 & 16.4 \\
C18:1 & 173.7 & 30.8 & 267.3 & 37.2 \\
\hline SFA & 253.0 & 46.6 & 275.7 & 38.4 \\
PUFA & 383.0 & 31.1 & 267.9 & 37.3 \\
\hline MUFA & 255.7 & 22.3 & 175.0 & 24.3 \\
n-6 & 182.0 & 21.5 & 170.2 & 23.7 \\
\hline n-3 & 176.7 & 0.8 & 4.7 & 0.6 \\
AI & 5.3 & & 0.41 & \\
\hline TI & 0.57 & & 1.16 & \\
\hline
\end{tabular}

SFA: saturated fatty acids; MUFA: monounsaturated fatty acids; PUFA: polyunsaturated fatty acids. AI: Atherogenic Index; TI: Thrombogenic Index. 
i) lower concentration of total lipids (1.6\% vs 5.3\%);

ii) lower cholesterol content $(41.3 \mathrm{mg} / 100$ g vs 60-90 mg/100 g);

iii) lower levels of AI Atherogenicity Index $(0.41 \pm 0.04$ vs $0.57 \pm 0.06)$ and of TI Thrombogenicity Index $(1.16 \pm 0.13 v s$ $1.63 \pm 0.13)$;

iv) higher content of vitamin B6 (0.44 $\mathrm{mg} / 100 \mathrm{~g}$ vs $0.30 \mathrm{mg} / 100 \mathrm{~g})$ and B12 $(1.28 \mathrm{mg} / 100 \mathrm{~g}$ vs $1.00 \mathrm{mg} / 100 \mathrm{~g})$.

v) higher concentration of iron (1.4 $\mathrm{mg} / 100 \mathrm{~g} v s 1.2 \mathrm{mg} / 100 \mathrm{~g})$ and zinc (4.0 $\mathrm{mg} / 100 \mathrm{~g}$ vs $3.2 \mathrm{mg} / 100 \mathrm{~g}$ );

Zhang et al. (2016) conducted a study on 6 buffalo females and 6 cattle females, native to the city of Nanning and Baoji,

Table 3. Comparison of the amino acid composition between buffalo and beef Longissimus dorsi muscle (adapted from Infascelli et al., 2009 with permission).

\begin{tabular}{lcc} 
Amino acid composition $(\mathrm{g} / \mathbf{1 6 g} \mathbf{N})$ & Buffalo & Beef \\
Isoleucine & 5.0 & 4.8 \\
Leucine & 8.1 & 8.1 \\
\hline Lysine & 8.4 & 8.9 \\
Methionine + Cystine & 3.9 & 4.0 \\
\hline Phenylalanine + Tyrosine & 6.7 & 8.0 \\
Threonine & 3.8 & 4.6 \\
Tryptophan & 1.0 & 1.1 \\
Valine & 4.5 & 5.0 \\
\hline
\end{tabular}

Table 4. Comparison of the vitamin composition between buffalo and beef Longissimus dorsi muscle (adapted from Infascelli et al., 2009 with permission).

\begin{tabular}{lcc} 
Vitamin composition $(\mathrm{mg} / \mathbf{1 0 0 g})$ & Buffalo & Beef \\
Thiamine (vit. B1) & 0.06 & 0.15 \\
Riboflavin (vit. B2) & 0.19 & 0.26 \\
\hline Niacin (vit. B3) & 6.30 & 6.30 \\
Pyridoxine (vit. B6) & 0.44 & 0.30 \\
\hline Cobalamin (vit. B12) & 1.28 & 1.00 \\
\hline
\end{tabular}

Table 5. Comparison of the mineral composition between buffalo and beef Longissimus dorsi muscle (adapted from Infascelli et al., 2009 with permission).

\begin{tabular}{lcc} 
Mineral composition $(\mathbf{m g} / \mathbf{1 0 0 g})$ & Buffalo & Beef \\
Calcium & 5.1 & 7.4 \\
Phosphorus & 181.1 & 109.4 \\
\hline Iron & 1.4 & 1.2 \\
Sodium & 74.6 & 61.9 \\
\hline Potassium & 290.3 & 312.4 \\
Zinc & 4.0 & 3.2 \\
\hline Magnesium & 24.2 & 25.7 \\
Chromium $(\mu \mathrm{g} / 100 \mathrm{~g})$ & 2.0 & 1.5 \\
\hline Manganese $(\mu \mathrm{g} / \mathrm{l} 00 \mathrm{~g})$ & 9.4 & 9.0 \\
Copper $(\mu \mathrm{g} / \mathrm{l} 00 \mathrm{~g})$ & 181.1 & 166.0 \\
\hline
\end{tabular}

teristics. The most intense color of buffalo meat was due to the greater amount of myoglobin contained in its muscles (Zhang et al., 2016).

According to these results, the buffalo meat is presented as a healthier alternative to the widespread beef. Further investigations, especially from an economic and organoleptic point of view, are needed to confirm these results and to stimulate the diffusion of this food in the Mediterranean diet.

\section{References}

Anagrafe Nazionale Zootecnica, 2018. Statistiche. Available from: http://statistiche.izs.it/portal/page? pageid=73,129 $18 \&$ dad=portal\&_schema=PORTAL\&op=elenco_rep\&p_report=plet_r ep_bov\&p_titolo- $=$ Bovini e Bufalini. Retrieved November 11, 2018,

Assocarni, 2018a. Il consumo apparente pro capite di carni in Italia. Roma.

Assocarni, 2018b. Il consumo pro capite di carni extra UE. Roma.

Assocarni, 2018c. Il consumo pro capite di carni nella UE. Roma.

Baltic M, Boskovic M, Ivanovic J, Janjic J, Dokmanovic M., Markovic R, Baltic T, 2014. Bioactive peptides from meat and their influence on human health. Tehnologija Mesa ID: 207308044

Barnard ND, Nicholson A, Howard JL, 1995. The medical costs attributable to meat consumption. Prev Med 24:646-55.

Bordoni A, Laghi L, Babini E, Di Nunzio M, Picone G, Ciampa A, Valli V, Danesi F, Capozzi F, 2014. The foodomics approach for the evaluation of protein bioaccessibility in processed meat upon in vitro digestion. Electrophoresis 35:1607-14.

Borghese A, 2005. Buffalo production and research, Buffalo Population and Strategies in the World. Rome: FAO.

Borghese A, 2013. Buffalo livestock and products in Europe. Buffalo Bull 32:50-74.

Brunner EJ, Mosdøl A, Witte DR, Martikainen P, Stafford M, Shipley MJ, Marmot MG, 2008. Dietary patterns and 15-y risks of major coronary events, diabetes, and mortality. Am J Clin Nutr 87:1414-21.

Calabrò S, Cutrignelli MI, Gonzalez OJ, Chiofalo B, Grossi M, Tudisco R, Panetta C, Infascelli F, 2014. Meat quality of buffalo young bulls fed faba bean as protein source. Meat Sci 96:591-6.

Chakrabarti S, Guha S, Majumder K, 2018. Food-Derived Bioactive Peptides in Human Health: Challenges and Opportunities. Nutrients 10:e1738.

Cifuni GF, Contò M, Amici A, Faill, S, 
2014. Physical and nutritional properties of buffalo meat finished on hay or maize silage-based diets. Anim Sci J 85:405-10.

Cordain L, Eaton SB, Miller JB, Mann N, Hill K, 2002. The paradoxical nature of hunter-gatherer diets: Meat-based, yet non-atherogenic. Eur J Clin Nutr $56: \mathrm{S} 42-52$.

Department of Health and Social Security, 1994. Nutritional aspects and cardiovascular disease: report on health and social subjects. HMSO, London.

Driskell JA, Marchello MJ, Giraud DW, 2000. Riboflavin and niacin concentrations of bison cuts. J Anim Sci 78:1267-71.

Driskell JA, Yuan X, Giraud DW, Hadley M, Marchello MJ, 1997. Concentrations of Selected Vitamins and Selenium in Bison Cuts. J Anim Sci 75:2950-4.

Ferranti P, Nitride C, Nicolai MA, Mamone G, Picariello G, Bordoni A, Valli V, Di Nunzio M, Babini E, Marcolini E, Capozzi F, 2014. In vitro digestion of Bresaola proteins and release of potential bioactive peptides. Food Res Int 63:157-69.

Galbraith JK, Hauer G, Helbig L, Wang Z, Marchello MJ, Goonewardene LA, 2006. Nutrient profiles in retail cuts of bison meat. Meat Sci 74:648-54.

Gariballa S, 2000. Review. Carnosine: physiological properties and therapeutic potential. Age Ageing 29:207-10.

Giordano G, Guarini P, Ferrari P, BiondiZoccai G, Schiavone B, Giordano A, 2010. Beneficial impact on cardiovascular risk profile of water buffalo meat consumption. Eur J Clin Nutr 64:1000-6.

Giuffrida-Mendoza M, Arenas de Moreno L, Uzcátegui-Bracho S, RincónVillalobos G, Huerta-Leidenz N, 2007. Mineral content of longissimus dorsi thoracis from water buffalo and Zebuinfluenced cattle at four comparative ages. Meat Sci 75:487-93.

Ilavarasan R, Abraham RJJ, Appa Rao V, Wilfred Ruban S, Ramani R, 2016. Effect of age on meat quality characteristics and nutritional composition of
Toda buffalo. Buffalo Bull 35:215-23.

Infascelli F, Cutrignelli MI, Bovera F, Tudisco R, Calabrò S, Zicarelli F, D’Urso S, Piccolo V, 2005. Cholesterol and fatty acid profile of meat from Marchigiana and buffalo bull. 1st Buffalo Symposium of Europe and the Americas, 146-157. Paestum.

Infascelli F, Roscia M, Buffardi F, 2009. La carne di Bufalo. Edizioni Pubblicità Italia.

Intakes DR, 2011. Dietary Reference Intakes (DRIs): Recommended Dietary Allowances and Adequate Intakes, Vitamins Food and Nutrition Board, Institute of Medicine, National Academies. Nutr Rev

Joele MR, Lourenço LF, Lourenço Júnior JB, Araújo GS, Budel JC, Garcia AR, 2017. Meat quality of buffaloes finished in traditional or silvopastoral system in the Brazilian Eastern Amazon. J Sci Food Agric 97:1740-5.

Keys A, 1980. Coronary heart disease, serum cholesterol, and the diet. Acta Med Scand 207:153-60.

Lambertz C, Panprasert P, Holtz W, Moors E, Jaturasitha S, Wicke M, Gauly M, 2014. Carcass characteristics and meat quality of swamp buffaloes (bubalus bubalis) fattened at different feeding intensities. Asian-Australas J Anim Sci 27:551-60.

Landi N, di Giuseppe AMA, Ragucci S, di Maro A, 2016. Free amino acid profile of Bubalus bubalis L. meat from the Campania region. Rev Brasil Zootec 45:627-31.

Larick DK, Turner BE, Schoenherr WD, Coffey MT, Pilkington DH, 1992. Volatile compound content and fatty acid composition of pork as influenced by linoleic acid content of the diet. J Anim Sci 70:1397-403.

Mancini RA, Hunt MC, 2005. Current research in meat color. Meat Sci 71:100-21.

Marcolini E, Babini E, Bordoni A, Di Nunzio M, Laghi L, Maczó A, Picone G, Szerdahelyi E, Valli V, Capozzi F, 2015. Bioaccessibility of the Bioactive
Peptide Carnosine during in Vitro Digestion of Cured Beef Meat. J Agric Food Chem 63:4973-8.

McDaniel J, Askew W, Bennett D, Mihalopoulos J, Anantharaman S, Fjeldstad AS, Rule DC, Nanjee NM, Harris RA, Richardson RS, 2013. Bison meat has a lower atherogenic risk than beef in healthy men. Nutr Res 33:293-302.

Ordovas JM, Ferguson LR, Tai ES, Mathers JC, 2018. Personalised nutrition and health. BMJ 361:bmj.k2173.

Scollan N, Hocquette JF, Nuernberg K, Dannenberger D, Richardson I, Moloney A, 2006. Innovations in beef production systems that enhance the nutritional and health value of beef lipids and their relationship with meat quality. Meat Sci 74:17-33.

Syed Ziauddin K, Mahendrakar NS, Rao DN, Ramesh BS, Amla BL, 1994. Observations on some chemical and physical characteristics of buffalo meat. Meat Sci 37:103-13.

Tateo A, De Palo P, Quaglia NC, Centoducati P, 2007. Some qualitative and chromatic aspects of thawed buffalo (Bubalus bubalis) meat. Meat Sci 76:352-8.

Trichopoulou A, Bamia C, Trichopoulos D, 2009. Anatomy of health effects of Mediterranean diet: Greek EPIC prospective cohort study. BMJ 338:b2337.

Ulbricht TLV, Southgate DAT, 1991. Coronary heart disease: seven dietary factors. The Lancet 338:985-92.

USDA, 2010. USDA National Nutrient Database for Standard Reference.

USDA, 2015. National Nutrient Database for Standard Reference, Release 28.

Verma M, Hontecillas R, Tubau-Juni N, Abedi V, Bassaganya-Riera J, 2018. Challenges in Personalized Nutrition and Health. Front Nutr 29;5:117.

Zhang Y, Wang H, Gui L, Wang H, Mei C, Zhang Y, Xu H, Jia C, Zan L, 2016. Profile of muscle tissue gene expression specific to water buffalo: Comparison with domestic cattle by genome array. Gene 577:24-31. 